\title{
SISTEM PAKAR PENENTUAN KUALITAS KENDARAAN BEKAS PADA BASOKA MOTOR DENGAN MENGGUNAKAN METODE FORWARD CHAINING
}

\author{
Yogi Wiyandra, Firna Yenila \\ Universitas Putra Indonesia YPTK Padang \\ 1'yogiwiyandra@upiyptk.ac.id, ${ }^{2}$ firnayenila@ upiyptk.ac.id,
}

\begin{abstract}
ABSTRAK
Kendaraan roda dua bukan merupakan kebutuhan tersier zaman sekarang, namun sudah menjadi kebutuhan primer, terutama bagi masyarakat yang memiliki akses jauh dari angkot atau kendaraan umum lainnya, maka kendaraan bermotor ini merupakan salah satu alternative yang digunakan sebagai penunjang. Kendaraan roda dua merupakan salah satu kendaraan yang banyak diminati masyarakat, dan tak jarang diantara masyarakat tersebut memilih kendaraan bekas dikarenakan hobi atau kebutuhan. Banyak diantara ketikan melakukan pembelian kendaraan bekas tanpa memahami kondisi kendaran terlebih dahulu. Dan tak jarang juga masyarakat yang memiliki pengetahuan awam mengenai kendaraan bermotor menjadi sasaran empuk penjual, untuk itu peneliti memberikan solusi dengan menciptakan sebuah sistem yang baru yang bisa dijadikan sebagai alternative untuk berkonsultasi, sistem ini dibangun dengan melibatkan pakar yang memahami kendaraan bermotor dengan menggunakan metoda forward chaining. Metode yang digunakan dalam penelitian ini adalah research dan development ( $\&$ D) dengan teknik pengumpulan data dilakukan secara deskriptif. Output dari penelitian ini adalah memberikan pengetahuan kepada masyarakat mengenai kendaraan bermotor dalam kondisi bekas, sehingga masyarakat lebih tau positif negatifnya kendaraan tersebut.
\end{abstract}

Keyword : Sistem Pakar, Mesin Motor, Motor Bekas, Forward Chaining

\section{PENDAHULUAN}

\subsection{Latar Belakang}

Kendaraan bermotor adalah kendaraan yang digerakkan oleh peralatan teknik dimana peralatan tersebut merupakan satu kesatuan sistim yang terdiri dari rangka landasan, bagianbagian motor penggerak, perangkat penerus daya, bodi kendaraan, perangkat rem, perangkat suspensi / roda, perangkat kemudi beserta kelistrikan yang saling mengadakan Inter relasi secarat tertib.Pengujian Kendaraan Bermotor adalah serangkaian kegiatan menguji yang memeriksa bagian-bagian, kendaraan bermotor, kereta gandengan, kereta tempelan dan kendaraan khusus dalam rangka pemenuhan terhadap persyaratan teknis dan laik jalan. Selanjutnya yang dimaksud dengan Penguji Kendaraan Bermotor adalah Pegawai Negeri Sipil yang diberi tugas, tanggung jawab, wewenang, dan hak secara penuh oleh pejabat yang berwenang untuk melakukan tugas pengujian kendaraan bermotor. Memiliki Sertifikat Kompetensi dan Tanda Kualifikasi Teknis Penguji Kendaraan Bermotor.

Pada saat sekarang pengguna kendaraan bermotor sudah semakin banyak, mulai dari sistem kerja manual ataupun matic, dengan semakin banyaknya pengguna kendaraan bermotor dan juga merk kendaraan dilapangan memungkinkan seseorang untuk menjual kembali kendaraan yang sudah dipakai dengan alasan tertentu dan bahkan karena ketertarikan dengan kendaraan dengan model yang baru. Serta banyak juga pengguna yang membeli kendaraan yang sudah pernah di pakai oleh seseorang yang dikarenakan berbagai factor, seperti hobi, kebutuhan dan 
lainnya. Mendekati permasalahan yang demikian di butuhkan seorang pakar untuk menentukan kualitas kendaraan beroda dua (motor) yang dengan tujuan motor tersebut nyaman dipakai atau digunakan pada waktu-waktu tertentu. Pakar kendaraan bermotor adalah seorang mekanik yang memiliki kesibukan ekstra sehari-harinya sehingga pengguna memiliki keterbatasan waktu untuk berdiskusi dengannya. Salah satu jawaban yang menarik dari permasalahan tersebut adalah dengan menghadirkan sebuah sistem pakar yang mampu membantu pengguna ketika membutuhkan tempat untuk berdiskusi atau berkonsultasi mengenai hal tesebut.

Sistem pakar (expert system) adalah sistem yang berusaha mengapdosi pengetahuan manusia ke komputer, agar komputer dapat menyelesaikan masalah seperti yang biasa dilakukan oleh para ahli. Sistem pakar yang baik dirancang agar dapat menyelesaikan suatu permasalahan tertentu dengan meniru kerja dari para ahli..

\subsection{Batasan Masalah}

Dalam penulisan penelitian ini ditentukan batasan studi sebagai berikut :

1. Bagaimana merancang system yang mampu membantu masyarakat dalam menentukan kualitas motor bekas?

2. Apakah expert system dengan metoda Forward Chaining dapat membantu masyarakat dalam mencari informasi mengenai kendaraan motor bekas?

3. Bagaimana menerapkan metoda Forward Chaining dalam penarikan kesimpulan menyediakan informasi?

\subsection{Rumusan Masalah}

Berdasarkan batasan masalah diatas dapat dirumuskan masalah dalam penelitian ini sebagai berikut:

1. Sistem pakar ini hanya membahas cara menentukan kualitas kendaraan bermotor terutama motor bekas.

2. Sistem pakar ini menghasilkan pengetahuan yang berupa deskriptif dari persentase kualitas kendaraan bermotor.

3. Sistem pakar ini menggunakan metode Forward Chaining.

\subsection{Tujuan Penelitian}

Tujuan dari penelitian ini adalah sebagai berikut:

1. Memahami sejauh mana sistem ini dapat menganalisa permasalahan yang ada.

2. Merancang aplikasi sistem pakar yang memberikan pengetahuan kepada pengguna tentang menentukan kualitas kendaraan bermotor yang bekas sebelum pembelian.

3. Menganalisa sejauh mana pemahaman pengguna mengenai kendaraan bermotor bekas.

4. Mengimplementasikan sistem pakar yang menggunakan metode Forward Chaining bagi pengguna.

5. Menguji sistem yang telah dibangun dan memperbaiki jika ada kesalahan pada sistem yang telah dibangun. 


\section{LANDASAN TEORI}

\subsection{Sistem Pakar}

Sistem pakar (expert system) adalah sistem yang berbasis komputer yang menggunakan pengetahuan, fakta, dan teknik penalaran dalam memecahkan masalah yang biasanya hanya dapat dipecahkan oleh seorang. Bagi para ahli sistem pakar juga membantu aktivitasnya sebagai asisten yang sangat berpengalaman. Sistem pakar juga dapat memberikan penganalisaan terhadap masalah dan juga dapat merekomendasikan pada penguna beberapa tindakan untuk melakukan perbaikan (Asabere\&Enguah, 2012).

Pengetahuan tentang sistem pakar dibentuk dari kaidah atau pengalaman tentang prilaku elemen dari domain bidang pengetahuan tertentu. Pengetahuan pada sistem pakar diperoleh dari orang yang mempunyai pengetahuan pada suatu bidang (pakar bidangtertentu), buku-buku, jurnal ilmiah, majalah, maupun dokumentasi cetak lainnya. Sumber pengetahuan tersebut bisa dikenal dengan sumber keahlian.

\subsection{Arsitektur Sistem Pakar}

Salah satu fitur yang harus dimiliki oleh sistem pakar adalah kemampuan untuk menalar. Jika keahlian-keahlian sudah tersimpan sebagai basis pengetahuan dan sudah tersedia program yang mampu mengakses basis data, maka komputer harus dapat diprogram untuk membuat inferensi.

Sebagian besar sistem pakar komersial dibuat dalam bentuk rule-based systems, yang mana pengetahuan disimpan dalam bentuk aturan-aturan.Aturan tersebut biasanya berbentuk IF-THEN (Sri Kusumadewi, 2003). Seperti gambar struktur sistem pakar berikut:

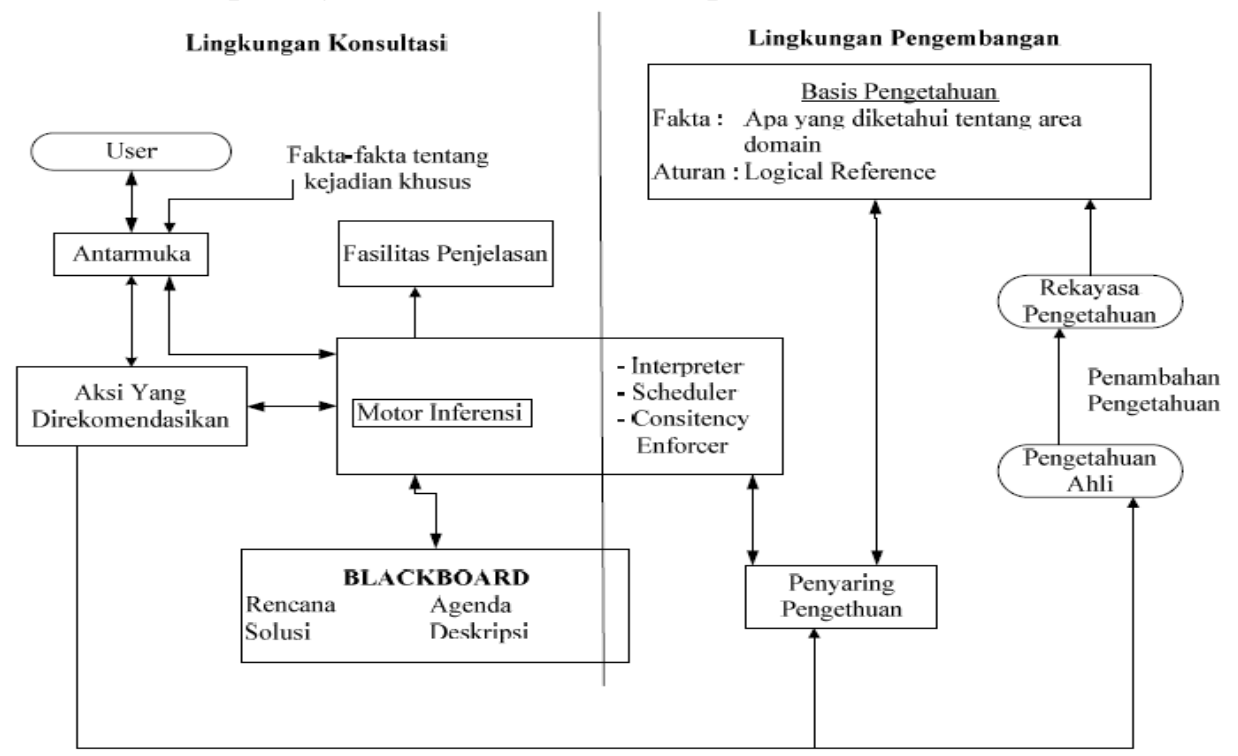

Gambar 2.3 Struktur Sistem Pakar

pada bagan sistem pakar tersebut jelas yang menyusun sistem pakar yaitu user interface (antarmuka pengguna), basis pengetahuan, akuisisi pengetahuan, mesin inferensi, work place, fasilitas penjelas dan perbaikan pengetahuan.

\subsection{Motor Inferensi (Inference Engine)}


Motor inferensi mengandung mekanisme pola pikir dan penalaran yangdigunakan oleh pakar dalam menyelesaikan suatu masalah dalam Sistem Pakar, yaitu Forward Chaining dan Backward Chaining.

Forward Chaining adalah metode inference engine yang mencocokan fakta atau pernyataan dimulai dari bagian sebelah kiri (if dulu). Inferensi Forward Chaining dapat dianggap sebagai strategi yang berasal dari sejumlah fakta yang diketahui. Pencarian dilakukan dengan mengunakan aturan yang premis sesuai dengan fakta yang diketahui untuk memperoleh faktafakta baru dan melanjutkan proses sampai tujuan tercapai. Forward Chaining juga dapat diartikan sebagai percocokan fakta atau pernyataan dimulai dari bagian sebelah kiri ( $I F$ dulu). Dengan kata lain penalaran dimulai dari fakta terlebih dahulu untuk menguji kebenaran hipotesis.

Tabel 2.1. Contoh Aturan-Aturan

\begin{tabular}{|l|l|}
\hline No & Aturan \\
\hline R-1 & IF A \& B THEN C \\
\hline R-2 & IF C THEN D \\
\hline R-3 & IF A \& E THEN F \\
\hline R-4 & IF A THEN G \\
\hline R-5 & IF F \& G THEN D \\
\hline R-6 & IF G \& E THEN H \\
\hline R-7 & IF C \& H THEN I \\
\hline R-8 & IF I \& A THEN J \\
\hline R-9 & IF G THEN J \\
\hline R-10 & IF J THEN K \\
\hline & \\
\hline
\end{tabular}

Pada tabel terlihat ada 10 aturan yang simpan dalam basis pengetahuan. Fakta awal yang diberikan hanya: A \& F (artinya: A dan F bernilai benar). Ingin dibuktikan apakah $\mathrm{K}$ benilai benar (hipotesis $\mathrm{K})$. Ingin diperoleh konklusi dari daftar konklusi yang ada berdasarkan premis-premis dalam aturan dan fakta yang diberikan oleh user. Berikut ini adalah daftar aturannya :

Aturan 9 :

Jika premis 1

Dan premis 2

Dan premis

Maka konklusi 1

Aturan 10 :

Jika premis 1

Dan premis 3

Dan premis 4

Maka konklusi 2

Aturan 11:

Jika premis 2

Dan premis 3

Dan premis 5

Maka konklusi 3

Aturan 12 : 
UPI YPTK Jurnal KomTekInfo Vol. 5, No. 1, Juni 2018, Hal. 23-34 ISSN :2356-0010 | elSSN :2502-8758

Copyright@2018 by LPPM UPI YPTK Padang

Jika premis 1

Dan premis 4

Dan premis 5

Dan premis 6

Maka konklusi 4

\subsection{Metode Pencarian}

\subsubsection{Pencarian Buta (Blind Search)}

Pencarian buta ada beberapa metode yang digunakan adalah :

1. Pencarian melebar pertama (Breadth First Search)

Pencarian dilakukan pada semua simpul dalam setiap level secara berurutan dari kiri ke kanan (Suyanto 2011). Jika pada satu level belum ditemukan solusi, maka pencarian dilanjutkan pada level berikutnya. Demikian seterusnya sampai ditemukan solusi.semua node pada level $n$ akan dikunjungi terlebih dahulu sebelum mengunjungi node-node pada level $n+1$. Pencarian dimulai dari kiri ke kanan, kemudian berpindah ke level berikutnya demikian pula dari kiri ke kanan hingga ditemukan solusi.

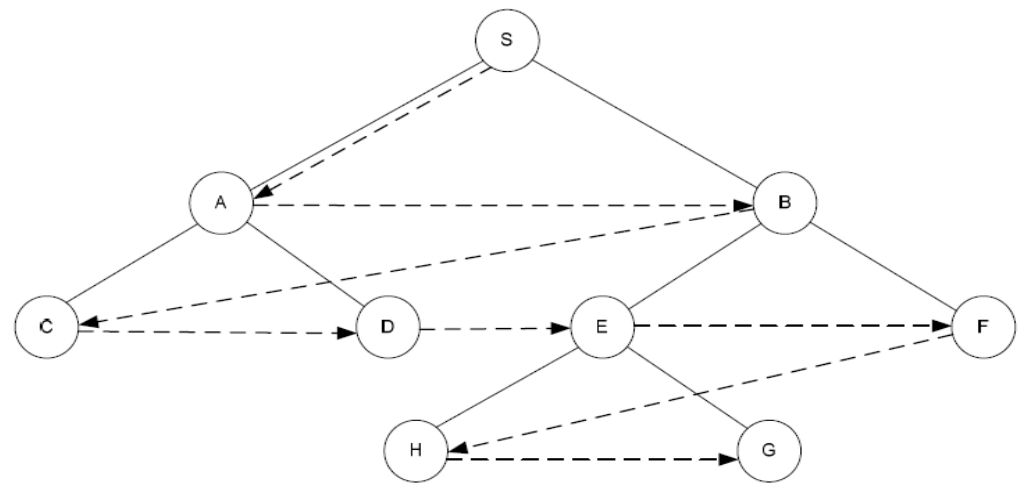

Gambar 2.5.Breadth First Searc

6. Pencarian Mendalam Pertama (Depth-First Search)

Pada Pencarian depth first search, proses pencarian akan dilakukan pada semua anaknya sebelum dilakukan pencarian ke node-node yang selevel. Pencarian dimulai dari node akar ke level yang lebih tinggi, proses ini diulangi terus hingga ditemukanya solusi.

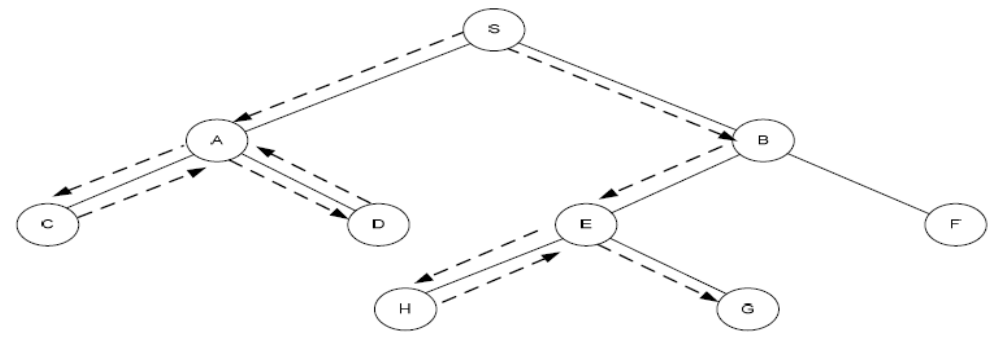

Gambar 2.6.Depth-First Search

\subsubsection{Pencarian Heuristik ( Heuristik Search)}

Pencarian buta tidak selalu dapat diterapkan dengan baik, hal ini disebabkan waktu aksesnya yang cukup lama serta besarnya memori yang diperlukan. Ada beberapa metode pencarian heuristik:

1. Pembangkitan dan Pengujian (Generate And Test) 
UPI YPTK Jurnal KomTekInfo Vol. 5, No. 1, Juni 2018, Hal. 23-34 ISSN :2356-0010 | elSSN :2502-8758

Copyright@2018 by LPPM UPI YPTK Padang

2. Pendakian Bukit (Hill Climbing)

3. Pencarian Terbaik Pertama (Best First Search)

\subsection{Kendaraan bermotor}

Kendaraan bermotor adalah kendaraan yang digerakkan oleh peralatan teknik untuk pergerakkannya, dan digunakan untuk transportasi darat. Umumnya kendaraan bermotor menggunakan mesin pembakaran dalam, namun motor listrik dan mesin jenis lain (misalnya kendaraan listrik hibrida dan hibrida plug-in) juga dapat digunakan. Kendaraan bermotor memiliki roda, dan biasanya berjalan di atas jalanan. Jenis-jenis kendaraan bermotor dapat bermacam-macam, mulai dari mobil, bus, sepeda motor, kendaraan off-road, truk ringan, sampai truk berat. Klasifikasi kendaraan bermotor ini bervariasi tergantung masing-masing negara. ISO 3833:1977 adalah standar untuk tipe dan definisi kendaraan darat.

Sampai tahun 2010, ada lebih dari 1 miliar kendaraan bermotor di seluruh dunia, tidak termasuk kendaraan off-road dan kendaraan berat. Kepemilikan kendaraan per kapita global adalah 148 kendaraan beroperasi tiap 1000 orang. Amerika Serikat adalah negara yang memiliki jumlah kendaraan bermotor terbanyak di dunia, dengan 239,8 juta kendaraan tahun 2010. Kepemilikan kendaraan per kapita di Amerika Serikat juga tertinggi di dunia, yaitu 769 kendaraan per 1000 penduduk. Republik Rakyat Tiongkok mempunyai jumlah kendaraan terbanyak kedua di dunia, dengan jumlah 78 juta unit dan sejak 2009 juga menjadi pasar kendaraan terbesar di dunia. Pada tahun 2011, 80 juta mobil dan kendaraan komersial diproduksi di seluruh dunia, 18,4 juta unit diantaranya diproduksi di Cina.

\section{ANALISIS DAN PERANCANGAN SISTEM}

Berdasarkan analisa sistem yang berjalan sehingga dapat dianalisa bahwa masih kurangnya pengetahuan masyarakat umumnya dan siswa khususnya mengenai kendaraan bermotor bekas. Dan hal tersebut memungkikan masyarakat atau pengguna kendaraan bermotor bekas mengalami kerugian dalam pembelian. Dan sistem pakar ini merupakan salah satu alternatif yang digunakan untuk memberikan informasi berupa ppengetahuan kepada pengguna dalam pembelian kendaraan bekas, sehingga si pengguna tidak perlu berkonsultasi kepada mekanik atau bagian yang ahli dalam kendaraan bermotor lagi. Pengguna akan lebih teliti dan jeli lagi dalam pemilihan kendaraan bermotor bekas secara mandiri

\section{Desain arsitektur sistem pakar penentuan kualitas kendaraaan bermotor bekas}

Desain arsitektur sistem pakar dalam menentukan kualitas kendaraan bermotor dapat dilihat pada gambar berikut: 


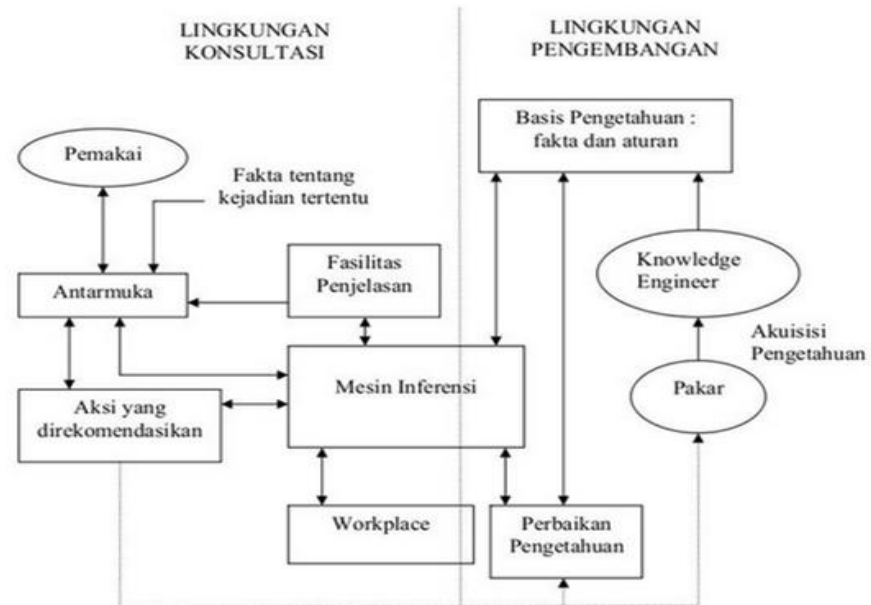

\section{Analisis Kebutuhan Sistem Pakar}

\section{Gambar 3.1 Arsitektur Sistem Pakar Kendaraan Bermotor}

a. Representasi Pengetahuan

Aktifitas ini bertujuan untuk mengidentifikasi kondisi kendaraan yang teridiri dari tiga fakta diantaranya kondisi mesin, tahun terbit kendaraan besera bidy kendaraan yang merupakan salah satu alternatif yang dijadikan penentu dalam pengambilan informasi mengenai kualitas kendaraan bermotor dengan kondisi bekas. Informasi tersebut didapatkan langsung dari mekanik atau orang yang memahami kendaraan bermotor. Adapun yang disimpan merupakan pengetahuan yang didasarkan pada keterkaitan antara kondisi mesin dengan tahun terbit kendaraan beserta body kendaraan tersebut hingga solusi terhadap kendaraan bekas yang berkualitaspun didapatkan. Jadi basis aturan yang digunakan melibatkan hubungan antara kategori kondisi mesin dengan tahun terbit dan body.

Tabel 3.1 Tabel Kondisi

\begin{tabular}{|l|l|}
\hline Id_kendaraan & Kondisi \\
\hline 001 & Mesin \\
\hline 002 & Body \\
\hline 003 & Kaki-Kaki \\
\hline 004 & Interior \\
\hline 005 & No rangka \& Mesin \\
\hline 006 & Aksesoris \\
\hline
\end{tabular}

Tabel 3.2 Tabel Usia

\begin{tabular}{|l|l|}
\hline Id_kend & Usia Kendaraan \\
\hline 001 & Tahun \\
\hline 002 & Surat-surat \\
\hline 003 & Pajak \\
\hline 004 & Harga \\
\hline
\end{tabular}

Tabel 3.3 Kesimpulan

\begin{tabular}{|l|l|l|}
\hline Id_kes & Masalah & Solusi \\
\hline
\end{tabular}




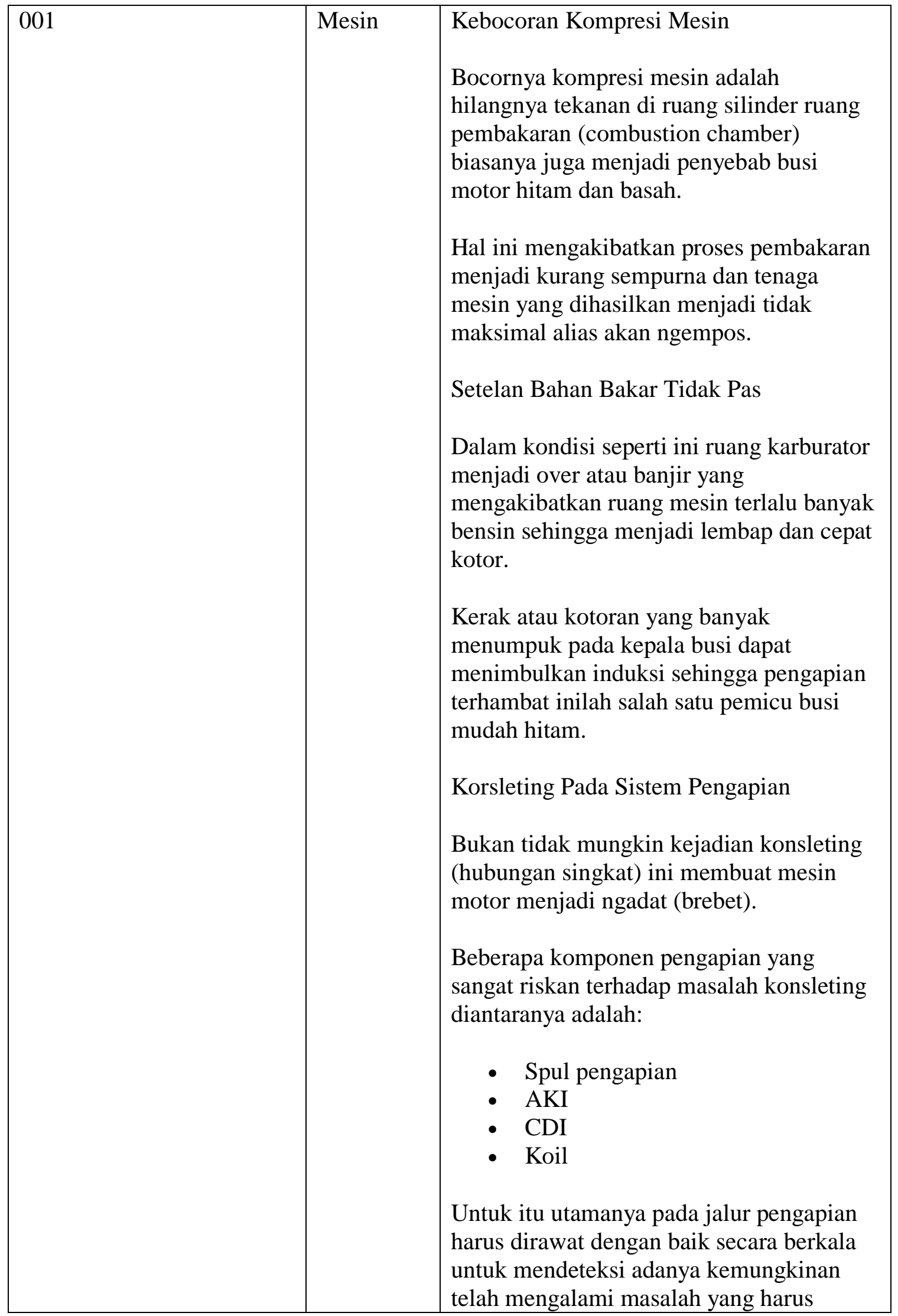




\begin{tabular}{|c|c|c|}
\hline & & $\begin{array}{l}\text { segera diantisipasi sebelum merembet pada } \\
\text { komponen lainnya. } \\
\text { Pemasangan Busi Kurang Tepat } \\
\text { Untuk busi baru biasanya memiliki ring } \\
\text { yang masih tebal sehingga seiring lamanya } \\
\text { penggunaan dan terus menerus terkena } \\
\text { panas maka akan terjadi perubahan } \\
\text { struktur material. }\end{array}$ \\
\hline 002 & Tahun & $\begin{array}{l}\text { Cek tahun pembuatan kendaraan tersebut. } \\
\text { Dengan cara melihat nomor rangka atau } \\
\text { VIN (vehicle identification number) } \\
\text { dimiliki oleh semua unit kendaraan } \\
\text { bermotor. Data sepanjang } 10 \text { karakter ini } \\
\text { juga digunakan oleh pihak kepolisian } \\
\text { sebagai tanda identitas kendaraan. } \\
\\
\text { VIN biasanya terpampang pada } \\
\text { kompartemen mesin atau kabin } \\
\text { penumpang. Dari } 17 \text { karakter yang } \\
\text { terpampang, karakter ke-10 adalah } \\
\text { penanda tahun pembuatan atau perakitan. }\end{array}$ \\
\hline 003 & Body & $\begin{array}{l}\text { Saudara diarahkan untuk melakukan } \\
\text { periksaan kondisi body motor, spion, dan } \\
\text { lain sebagainya apakah ada bagian bagian } \\
\text { part yang masih original atau tidak atau ada } \\
\text { cacat, perhatikan dengan baik komponen } \\
\text { komponen diatas. }\end{array}$ \\
\hline 004 & No Rangka & $\begin{array}{l}\text { Sebelum melakukan pembelian kendaraan } \\
\text { bermotor saudara diarahkan untuk } \\
\text { kelurusan roda motor depan dan belakang } \\
\text { apakah masih lurus atau ada sesuatu yang } \\
\text { mengganjal. dan pastikan bahwa rangka } \\
\text { atau sasis motor tersebut tidak ada } \\
\text { kebengkokkan. Jalankan motor sekitar } 40 \\
\text { Jm/jam dan rekan rem sedikit mendadak, } \\
\text { untuk memastikan bahwa motor tidak sulit } \\
\text { untuk dikendalikan ,hal yang barusan saya } \\
\text { ceritakan diatas akan berguna juga untuk } \\
\text { mendeteksi lurusnya sasis dan poros setang. }\end{array}$ \\
\hline
\end{tabular}

\section{Pengujian dan implementasi}

Tahapan dalam uji coba program adalah sebagai berikut: 
a. Tampilan menu login

Tampilan ini merupakan tampilan awal bagi pengguna sistem, baik user admin, member ataupun pakar akan menggunakan tampilan ini pertama kkalinya. Tampilan login bisa dilihat pada gambar berikut:

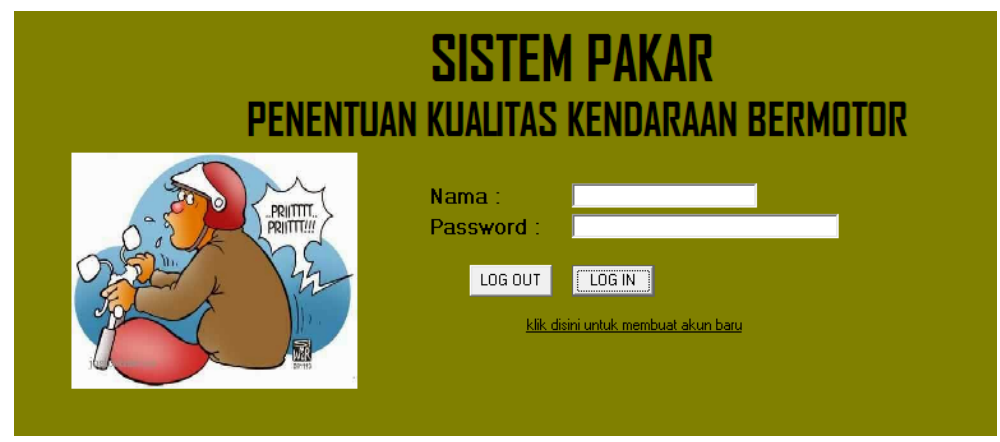

Gambar 3.2 Tampilan Log In

Setelah melakukan pengisian pada tapilan diatas maka sistem akan menuju pada tampilan sistem kedua yang menyajikan informasi untuk pakar, admin dan user member seperti pada tampilan berikut:

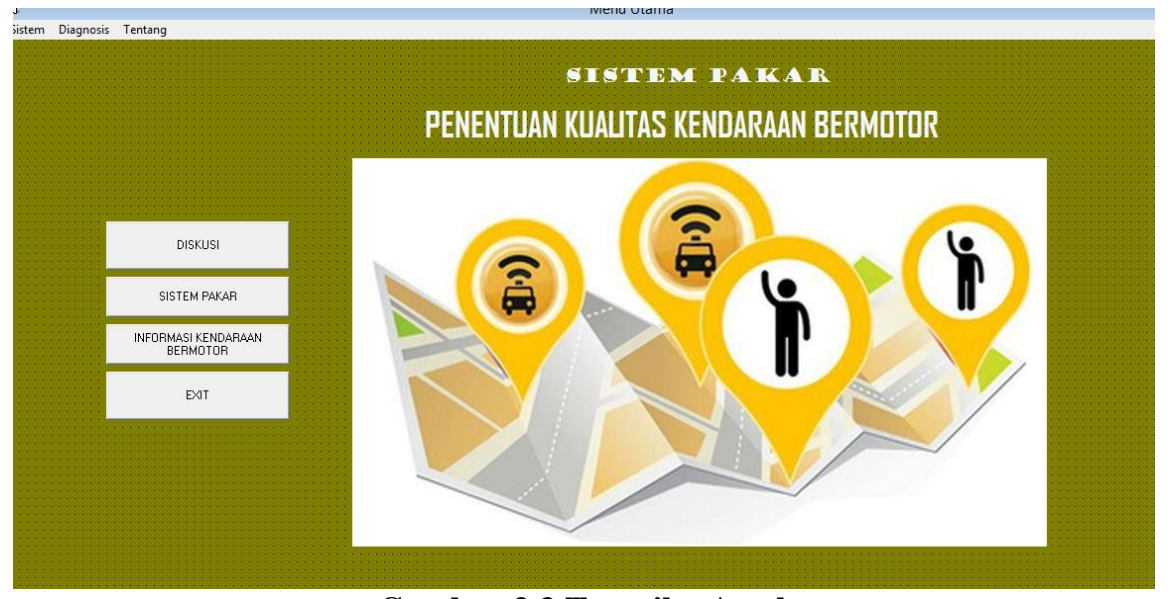

Gambar 3.3 TampilanAwal

Dari tampilan diatas diberikan informasi atau tindakan apa yang harus dilakukan oleh user dalam menggunan sisttem tersebut. User akan diarahkan pada icon sistem pakar untuk konsultasi selanjutnya atau dengan klik toolbar konsultasi di kiri atas.

2. Tampilan menu konsultasi

Tampilan menu konsultasi dapat dilakukan setelah user memilih menu konsultasi atau diagnose. Menu konsultasi merupakan implementasi dari menu algoritma certainty factor untuk memperoleh input atau data dari user yang akan dip roses dalam working berdasarkan knowledge base hingga menghasilkan kesimpulan

Proses konsultasi ini merupakan fasilitas pertama yang disediaka oleh program sistem pakar, pemilihan gejala tersebut merupakan kemungkinan gejala-gejala dari kendaraan yang di lihat langsung eleh user. Untuk lebih jelasnya seperti yang ditampilkan pada gambar berikut: 


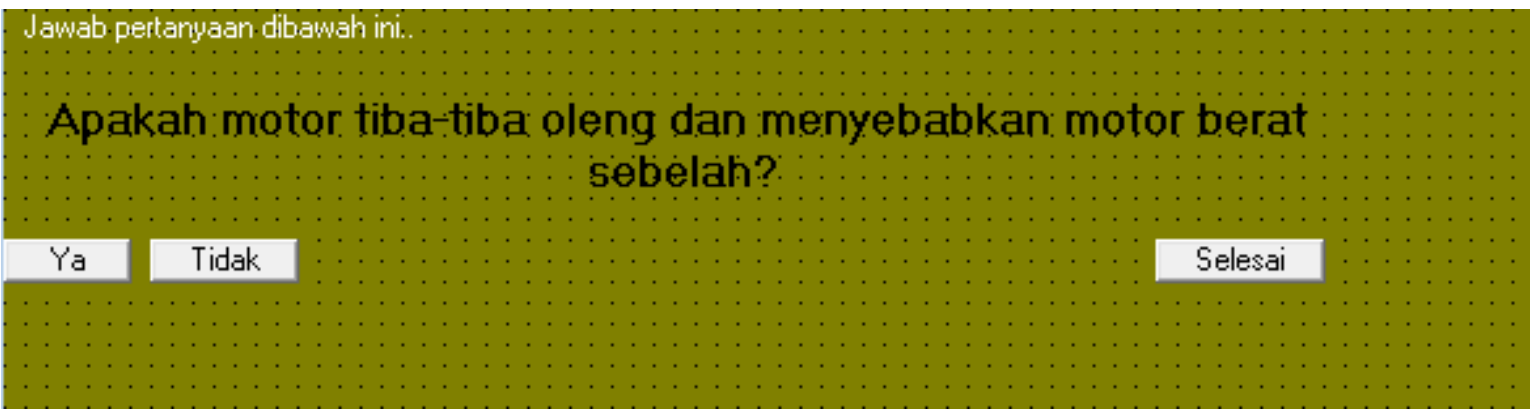

\section{Gambar 3.4 Tampilan Konsultasi}

Konklusi dari kasus tersebut salah satunya adalah :

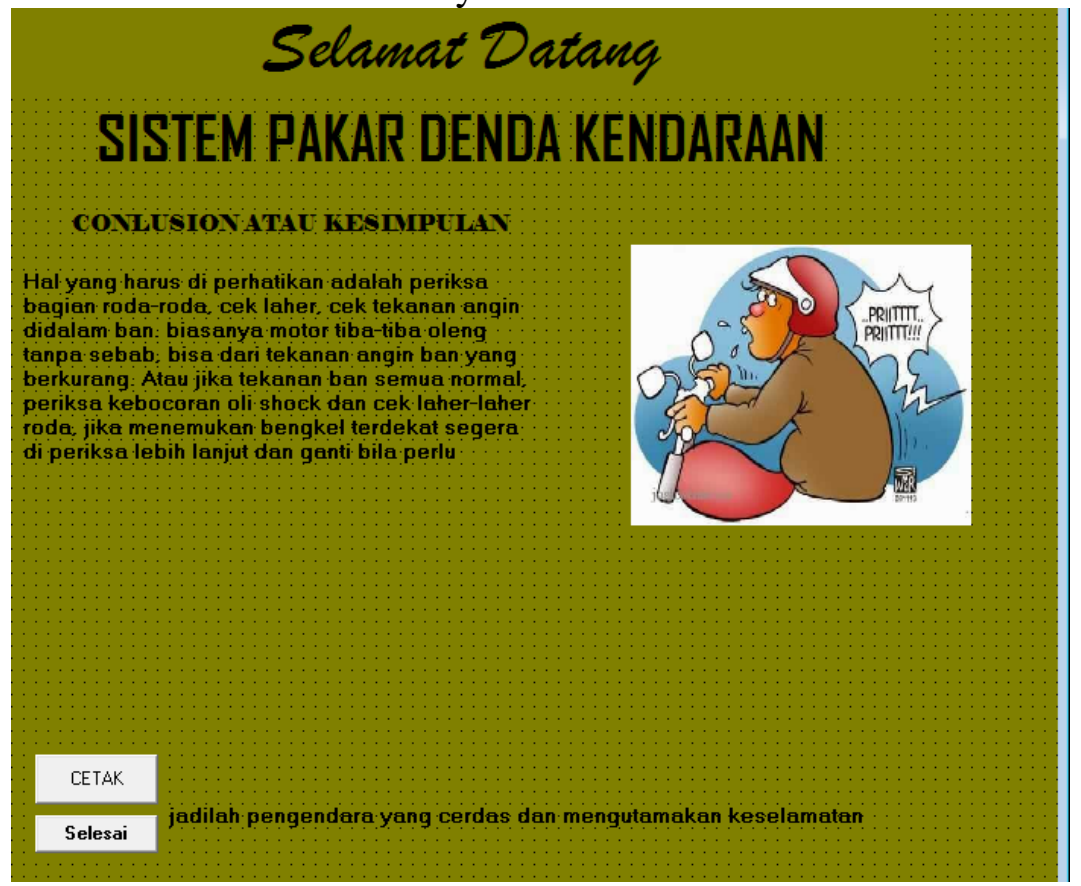

Gambar 3.5 Konklusi

\section{KESIMPULAN}

Berdasarkan analisis dan pembahasan yang dilakukan, maka dapat disimpulkan beberapa hal sebagai berikut :

1. Ada beberapa faktor yang dapat menentukan solusi dari penentuan kendaraan bermotor yang dihadapi. Faktor yang mempengaruhi tersebut diperoleh dari beberapa pilihan yang diberikan sistem, sehingga akan dihasilkan perencanaan sistem pakar untuk menentukan hal-hal yang harus dilakukan pada saat pengambilan kendaraan motor bekas.

2. Sistem yang dirancang dapat memberikan informasi kepada user berdasarkan data pilihan user yang dimasukan.

3. Penalaran forward chaining bisa digunakan untuk melakukan penelusuran faktor-faktor dan kriteria-kriteria untuk mendapatkan hasil dalam menentukan aktivitas yang sesuai untuk mendapatkan informasi seputar pernikahan dan solusi yang akan didapatkan. 
UPI YPTK Jurnal KomTekInfo Vol. 5, No. 1, Juni 2018, Hal. 23-34 ISSN :2356-0010 | elSSN :2502-8758

Copyright@2018 by LPPM UPI YPTK Padang

4. Output dari sistem ini dalam bentuk informasi yang dikaji berdasarkan kondisi user pada saat menggunakan sistem, dan hasil dapat di sajikan dalam bentuk hard copy.

\section{DAFTAR PUSTAKA}

Asabere, Yaw, Nana (2012), “Integration Of Expert System In Mobile Learning”, ICT Journal, Ghana Fitriani, dkk (2012), "Sistem Pakar Pada Bidang Teknologi Informasi Rekomendasi Profesi Pekerjaan Berdasarkan Kepribadian Mengguanakan Pendekatan Personality Factor", Universitas Brawijaya, Malang Gupta, Swati dan singhal, Ritika (2013). "Fundamental and Charasteristics Of an Expert System". Shobhit University: India

Hartati, Sri dan Iswanti, Sari (2008). "ImplementasiSistem Rule-Based Expert System Dalam Mendeteksi Kerusakan Jaringan Komputer Dengan Metode Backward Chaining Penanggulangannya”. Jurnal Saintikom: Medan

Kusrini (2006).“Sistem Pakar Teori Dan aplikasi”. Andi Offset: Yogyakarta

Kusumadewi, Sri (2003)."Artificial Intelligence (Teknik dan aplikasinya)". Graha Ilmu: Yogyakarta

Sasmito, dkk (2011). "Aplication Expert System Of Forward Chaining and The Rule Base Reasoning For Simulation Diagnose Pest Disease Red Onion and Chili Plant". ICISBC : Semarang

Suyanto (2011). "Kecerdasan Buatan". Andi: Yogyakarta Yowono, Bambang (2010). "Pengembangan Sistem Pakar Pada Perangkat Mobile Untuk Mendiagnosa Penyakit Gigi”.UPN Veteran: Yogyakarta Dany (2009).”Pengembangan Sistem Pakar Menggunakan Visual Basic". Andi: Yogyakarta

Usman, Rachmadi Usman. (2003) "Pilihan Penyelesaian Sengketa di Luar Pengadilan”. Bandung: Citra Aditya Bakti 